\title{
Un libro sobre el Abate Henri Breuil
}

\author{
martí Mas Cornellà
}

Hubo una época en que los calificativos wild o sauvages aplicados a las regiones de la Península Ibérica eran frecuentes en los textos de los viajeros y naturalistas ingleses y franceses que se sentian atraídos por diferentes aspectos de nuestra geografía.

A través de espesos y pegajosos barrizales, la pobre caballería se fue, sin prisas, a otro vado, que atravesamos también. Pronto apareció, como un farol en la noche, la luz del hogar en el que bailaba la llama, proyectando su resplandor por la puerta, grande y abierta de la casucha de Antonio. Tras una cena frugal y de la acostumbrada charla con mis huéspedes, volví entre las rocas del barranco vecino a la pequeña cueva baja, donde, sobre un lecho de paja, yo dormía desde hacia diez días enrollado en mis mantas. Para descubrir la entrada no era suficiente mi lámpara de carburo, cuyos fulgores hacían brillar, en el suelo húmedo del indefinido sendero, las pequeñas pajas con que lo había jalonado, una tarde en que vanamente erraba por la maleza en busca de este abrigo. En su absoluto aislamiento, lo prefería al camastro en la cabaña de Antonio, donde por la noche, unos contrabandistas habladores venían de visita, charlando ruidosamente. Allí nadie me distraía, a no ser las discretas idas y venidas de los ratones, los maullidos graves de un gato salvaje o el monótono ramoneo del ganado en las pendientes cercanas. No obstante, algunas noches se desencadenaba el terrible Levante; en otras, cuando la formidable voz del oleaje de Trafalgar me liegaba en alas de un temporal del Sudoeste, la montaña parecía trepidar sobre su base y se hubiese dicho que, bajo este asalto furioso, iba a volar como una simple paja. Pero apenas el alba sonrosaba el horizonte, la calma renacia. Entonces, sacudiendo el polvo, me entregaba a abluciones al aire libre, en algún agujero natural donde el agua de lluvia se había acumulado. [Texto de Henri Breuil recopilado por Camille Pitollet (1920:241) y traducido por Eduardo Ripoll Perelló (1994:130-131)].

En este momento el Abate Henri Breuil -sobre quien el Profesor Eduardo Ripoll Perelló ha elaborado un libro publicado recientemente que por su interés e importancia creemos merece un extenso comentario 
(Ripoll Perelló, 1994) - iniciaba sus visitas a España. Ninguno como él, sin embargo, contribuiría a desarrollar, a partir de estos conocimientos eruditos, una ciencia. El fragmento que destacamos a continuación, extraído casi al azar de la obra recensionada es ilustrativo y puede aplicarse no sólo al Paleolítico sino también al arte postpaleolítico y otras facetas o momentos de la Prehistoria. Los trabajos del Abate en algunos casos y por lo que respecta a la documentación de manifestaciones rupestres, por ejemplo, todavía no han sido revisados, y siguen citándose ineludiblemente como obras de referencia obligada, o lo están siendo recientemente, en otros han supuesto un punto de partida sin el cual no podrían haberse desarrollado investigaciones y teorias que incluso, muchas veces, permiten refutar sus hipótesis, lo cual no impide, sin embargo, valorar el impresionante trabajo realizado por este personaje.

Ya en aquel tiempo, [...], combinando sus conocimientos de Geologia, Paleontología, Tipología, Etnografía Prehistórica y Arte, supo dar una nueva perspectiva "histórica" de la evolución humana en las larguísimas edades de los grandes cazadores. En el porvenir, con el conocimiento de nuevos yacimientos y el perfeccionamiento de las técnicas de datación y de excavación estratigráfica, esta visión se hizo más amplia y precisa. (Ripoll Perelló, 1994:88).

Eduardo Ripoll Perelló comenta en la introducción al libro El Abate Henri Breuil (1877-1961) que para conocer la historia de la investigación, en este caso de la Prehistoria, es necesario aproximarse a las circunstancias en que vivieron las personas que la desarrollaron, especialmente sus máximos representantes. De sus palabras se desprende que debe reivindicarse la biografia, que ha quedado en cierta forma desprestigiada por diferentes motivos que nada tienen que ver con su esencia, como una forma de historiografía.

El volumen está estructurado en veinte cortos capítulos titulados de forma sugerente que hacen que el texto sea de fácil lectura. Es un libro para ser leído por los interesados en el tema de un tirón en una tarde.

Sin embargo no nos engañemos, pronto nos daremos cuenta que también es un trabajo muy útil para ser consultado y que casi sin que nos demos cuenta aporta un volumen de información realmente poco habitual. Trescientas dieciocho notas a pie de página nos remiten a una extensa bibliografía, introducen a una corta y concisa biografía de los personajes citados en el texto con una síntesis de sus publicaciones más destacadas o de interés en relación al tema por el cual se los menciona, y, en algunas ocasiones, presentan una contextualización sociológica. Se combinan las anécdotas, siempre sugerentes, con interesantes datos sobre actuales in- 
vestigaciones realizadas en lugares descubiertos a principios de siglo, las vicisitudes de las publicaciones, la creación de instituciones, la organización de reuniones científicas o las relaciones entre prehistoriadores, que muchas veces y de forma implícita han condicionado el desarrollo de las diferentes teorías arqueológicas.

"Infancia y primeros estudios», "Del Seminario de Saint-Sulpice a las cuevas con arte", "Un destino: el arte de los hombres prehistóricos", "La reivindicación de Altamira», "Actividad académica y maduración de una ciencia», "Alberto I de Mónaco y el Institut de Paléontologie Humaine de París», "El arte cantábrico y su apéndice andaluz», "Levante, Batuecas y Andalucia», "Buscando el Jardín de las Hespérides", "Los años de la postguerra", "Paréntesis africano y asiático», "El arte levantino y el problema de su cronología", "Una visión ecuménica de la Prehistoria», "Cronología y significado del arte paleolítico", "Lascaux, la segunda Altamira", "En tierra de exilio: El Africa austral", "La Dama Blanca del Brandberg y otros viajes», "El Papa de la Prehistoria», "Mirando al pasado" y «El fenómeno humano y la luz que se estingue». Son los veinte capítulos cuyos títulos resumen la obra. El trayecto a través de la vida privada, académica y científica del Abate Henri Breuil, haciendo hincapié en sus viajes y especialmente estancias en España, enmarcado en el análisis histórico de la época en que vivió -enfatizando especialmente la importancia de la primera y segunda guerras mundiales y el período que transcurre entre ambas, que suponen la transición hacia un mundo absolutamente nuevo, totalmente distinto al imperio del eurocentrismo en que se educó la generación que nació en el último cuarto del siglo $x \mathrm{Ix}$-, se detiene en los principales acontecimientos y temas candentes o problemáticos en relación a la ciencia que fue consolidándose durante la primera mitad del siglo $x x$. El descubrimiento y reivindicación de la Cueva de Altamira y otras innumerables investigaciones - reproducciones de arte rupestre, excavaciones, publicaciones ...- y hallazgos importantes, la batalla del Auriñaciense y las subdivisiones del Paleolítico Superior, la creación del Institut de Paléontologie Humaine, los trabajos sobre el arte paleolítico cantábrico y andaluz y el postpaleolítico de Levante, Batuecas y Andalucia, las investigaciones en Extremo Oriente, el estudio de la Dama Blanca del Brandberg y el arte rupestre sudafricano, la cronología del arte levantino, el significado del arte paleolítico, la atribución cultural de la Cueva de Lascaux...

El libro está ilustrado con interesantes fotografías, dibujos e ilustraciones que constituyen todo un documento histórico. Impresiona la fotografía del gran vestíbulo de la Cueva de Bédeilhac tomada a finales de septiembre de 1945 con restos de aviones (los alemanes utilizaron durante la se- 
gunda guerra mundial este yacimiento como factoría para montar aeroplanos) y sorprende la imagen del joven Henri Breuil con incontables manchas blancas de estearina en su sotana en el exterior de la Cueva de Altamira en 1902 (el sistema de iluminación utilizado para la copia de las representaciones artísticas eran velas sostenidas por candelabros ya que la lámpara de acetileno todavía no estaba en uso).

La obra culmina con una bibliografía con ochocientos treinta y cuatro títulos, que como señala el autor, no es demasiado conocida ni, tampoco, muy utilizada. Ciento setenta y cinco referencias se refieren a la Prehistoria española e incluyen artículos, notas, recensiones y, evidentemente, libros fundamentales. El último artículo relacionado es un trabajo que por determinadas circunstancias permaneció inédito durante veinticinco años y finalmente fue publicado en homenaje al Abate en la revista científica especializada Ars Praehistorica. Aunque se trata de la recopilación más completa publicada hasta ahora no pretende ser exhaustiva, ya que la extensa obra de Henri Breuil hace pensar que del mismo modo que contiene títulos poco conocidos pueden haberse omitido otros publicados en lugares difícilmente accesibles, por lo que el Profesor Ripoll Perelló considera que debería ser precisada, revisada y ampliada, tarea que intuímos ardua.

A medida que leemos esta biografía nos vamos dando cuenta que sólo ha podido ser escrita por una persona que fue discípulo, colaborador y amigo del Abate y también compartió una profunda amistad con otros muchos colaboradores y discípulos, a los que frecuentemente -como señala en la introducción - da la palabra para que el relato tenga una mayor autenticidad. Se introducen así un importante número de textos cortos, generalmente traducciones, en algunos casos difícilmente localizables y en otros inéditos. En este sentido destaca, junto a una considerable bibliografía consultada y recopilada a lo largo de años de trabajo, el Archivo E. R., conjunto de papeles donados por el Abate Henri Breuil al autor a título personal, principalmente correspondencia con profesores universitarios y eruditos españoles. Entre estos documentos destaca el prefacio, "Mis trabajos sobre el arte paleolítico en España (1902-1954)", un prólogo escrito en 1960 para un libro que finalmente no fue publicado y que se basa en sus carnés de viaje por España.

Debemos agradecer al Profesor Eduardo Ripoll Perelló este importante estudio, que aunque no pretenda ser un trabajo "total" es una versión exhaustiva que orienta sobradamente al interesado si en algún momento quiere profundizar en cualquier aspecto. La obra podría ser más extensa pero dudamos que pudiera ser más completa. La ingente labor investiga- 
dora del biografiado, en un período en que los nuevos descubrimientos se sucedian sin cesar y las interpretaciones eran siempre las primeras que se desarrollaban, parece pesar sobre el autor que probablemente teme que el lector no aprecie esta desbordada actividad excepcional, la cual creemos queda perfectamente reflejada, y podemos fácilmente darnos cuenta de que esta aportación no sería posible si no se hubiera dedicado a ella mucho tiempo, recopilando información y publicando varios ensayos (Ripoll Perelló, 1953, 1962, 1964, 1966, 1986-1987, 1988a, 1988b), de los cuales el que comentamos viene a ser la revisión más ampliada y puesta al día, aunque algunos de ellos tratan también más detalladamente algunas cuestiones concretas, por lo que no dejan de tener interés.

\section{BIBLIOGRAFÍA}

Pitollet, Camille, 1920, “L'Abbé Breuil et son Journal d'Espagne», Hispania, págs. $232-243$ y 259-299.

Ripoll Perelló, Eduardo, 1953, «A propósito de un aniversario. El Abate Breuil y el arte rupestre español", Altamira, 1-2-3, 15 págs., 3 fotografías.

- 1962, "Necrología. Abate Henri Breuil (1877-1961)", Ampurias, XXIV, págs. 353-354, 1 figura.

- 1964, "Vida y obra del Abate Henri Breuil, padre de la Prehistoria", (E. Ripoll Perelló, editor): Miscelánea en homenaje al Abate Henri Breuil (1877-1961). I, Instituto de Prehistoria y Arqueología de la Diputación Provincial de Barcelona (Monografías, XIV), Barcelona, págs. 1-69, 7 figs., XXV láms., ilustraciones.

- 1966, «Exposición dedicada al Abate Breuil en la Fondation Singer-Polignac, de París (1966)", Ampurias, XXVIII, págs. 303-304.

- 1986-1987, "A los veinticinco años de la muerte del Abate Henri Breuil», Ars Praehistorica, V-VI, págs. 13-19, ilustraciones.

- 1988a, "Abate H. Breuil y Coronel W. Verner: textos sobre la Cueva de la Pileta», (E. Ripoll Perelló, editor): Actas del Congreso Internacional El Estrecho de Gibraltar. Ceuta, noviembre de 1987. I: Prehistoria e Historia de la Antigüedad, Universidad Nacional de Educación a Distancia, Madrid, págs. 173-181, ilustraciones.

- 1988b, "Cartas al Abate Henri Breuil referentes al descubrimiento de Minateda", Homenaje a Samuel de los Santos Jener, Instituto de Estudios Albacetenses, Albacete, págs. 59-64.

- 1994, El Abate Henri Breuil (1877-1961), prefacio de H. Breuil, Universidad Nacional de Educación a Distancia (Aula Abierta, 79), Madrid, 375 pág., XLVIII láms., ilustraciones (21 x $14,5 \mathrm{~cm}$ ). 